\title{
HUBUNGAN ANTARA TINGKAT PENGETAHUAN TENTANG DIABETES MELLITUS DAN GAYA HIDUP DENGAN TIPE DIABETES MELLITUS DI PUSKESMAS WONODADI KABUPATEN BLITAR
}

\author{
Wizna Choirul Amalia \\ Ekawati Sutikno \\ Reny Nugraheni \\ Institut Ilmu Kesehatan Bhakti Wiyata Kediri
}

\begin{abstract}
Based on data obtained from the office of blitar district health , the incident Diabetes Mellitus fall into the order to 8 out of 10 largest disease, puskesmas who ranks first with of diabetes mellitus are puskesmas wonodadi Diabetics Mellitus year 2014 at puskesmas wonodadi 1.178 people as much as . This research aims to understand the relationship between the level of knowledge about Diabetes mellitus and life style to puskesmas wonodadi diabetes mellitus in the blitar district. The kind of research used is analytic survey by using technic sampling purposive of sampling. Population as many as 37 respondents and 37 samples from respondents. The collection of data using a questionnaire. To analyze the relationship between the level of knowledge about diabetes mellitus and lifestyle against diabetes mellitus scene used statistical tests bivariate test with using chi square. The results of research known that the level of knowledge 10,82 percent of respondents having enough and 89,18 percent of respondents having a level of lacking knowledge. Of respondents having the style of life is not healthy by 67,6 percent while respondents who have a healthy lifestyle by $32,4 \%$. Of the chi square statistics showed there was an association between the level of knowledge of diabetes mellitus with an occurrence diabetes mellitus of $0,027<$ $\alpha=0.05$, and there was an association between lifestyle with an occurrence diabetes mellitus of $0,049<\alpha=0.05$.
\end{abstract}

Keywords: knowledge , life Style, diabetes mellitus

\begin{abstract}
Abstrak: Berdasarkan data yang diperoleh dari Dinas Kesehatan Kabupaten Blitar, Tipe Diabetes mellitus masuk pada urutan ke 8 dari 10 penyakit terbesar, puskesmas yang menempati urutan pertama dengan penyakit Diabetes mellitus adalah puskesmas Wonodadi. Penderita Diabetes mellitus tahun 2014 di Puskesmas Wonodadi sebanyak 1.178 orang. Penelitian ini bertujuan untuk mengetahui hubungan antara tingkat pengetahuan tentang Diabetes mellitus dan gaya hidup terhadap Tipe Diabetes Mellitus di Puskesmas Wonodadi Kabupaten Blitar. Jenis penelitian yang digunakan adalah survey analitik dengan menggunakan tehnik sampling purposive sampling. Populasi dan sampel sebanyak 37 responden. Pengumpulan data menggunakan kuesioner. Untuk menganalisis hubungan antara tingkat pengetahuan tentang Diabetes mellitus dan gaya hidup terhadap Tipe Diabetes mellitus menggunakan uji chi square. Hasil penelitian diketahui sebesar $10,82 \%$ responden memiliki tingkat pengetahuan cukup dan sebesar $89,18 \%$ responden memiliki tingkat pengetahuan kurang. Responden memiliki gaya hidup tidak sehat sebesar 67,6\%. Dari uji statistik chi square menunjukan ada hubungan antara tingkat pengetahuan tentang Diabetes mellitus dengan Tipe Diabetes mellitus sebesar $0,027<\alpha=0,05$, dan ada hubungan antara gaya hidup dengan Tipe Diabetes mellitus sebesar $0,049<\alpha=0,05$.
\end{abstract}

Kata kunci: pengetahuan, gaya hidup, diabetes mellitus

Diabetes Mellitus (DM) merupakan salah satu penyakit yang prevalensinya terus mengalami peningkatan di dunia, baik pada negara maju ataupun negara berkembang, sehingga dikatakan bahwa DM sudah menjadi masalah kesehatan 
atau penyakit global pada masyarakat. Organisasi kesehatan dunia atau WHO memperkirakan bahwa lebih dari 346 juta orang di seluruh dunia mengidap DM. Jumlah ini kemungkinan akan lebih dari dua kali lipat pada tahun 2030 tanpa intervensi. Hampir $80 \%$ kematian DM terjadi di negara berpenghasilan rendah dan menengah. (Suiraoka, 2012).

Laporan dari Badan Penelitian dan Pengembangan Kesehatan Kementrian Kesehatan tahun 2013 menyebutkan terjadi peningkatan prevalensi pada

penderita DM yang diperoleh berdasarkan wawancara yaitu $1,1 \%$ pada tahun 2007 menjadi 1,5\% pada tahun

2013 sedangkan prevalensi DM berdasarkan diagnosis dokter atau gejala pada tahun 2013 sebesar 2,1\% dengan prevalensi terdiagnosis dokter tertinggi pada daerah Sulawesi Tengah (3,7\%) dan paling rendah daerah Jawa Barat $(0,5 \%)$. Prevalensi dari penderita DM cenderung meningkat pada perempuan dibandingkan dengan laki-laki dan terjadi peningkatan prevalensi penyakit DM sesuai dengan pertambahan umur namun mulai umur $>65$ tahun cenderung menurun dan cenderung lebih tinggi bagi penderita yang tinggal diperkotaan dibandingkan dipedesaan. (RISKESDAS, 2013).

Berdasarkan data yang diperoleh dari Dinas Kesehatan Kabupaten Blitar. DM masuk pada urutan ke 8 dari 10 penyakit terbesar. Angka kejadian DM pada tahun 2012 sebanyak 2.557 orang, pada tahun 2013 terdapat 3.791 orang dan pada tahun 2014 sebanyak 6.179 orang. Dari 24 puskesmas di Kabupaten Blitar, puskesmas yang menempati urutan pertama dengan penyakit DM adalah puskesmas Wonodadi. Data yang diperoleh dari Dinas Kesehatan Kabupaten Blitar data penderita DM di puskesmas Wonodadi tahun 2014 sebanyak 1.178 orang. (Dinas kesehatan kabupaten Blitar, 2014).

Melihat kenaikan prevalensi terjadinya Diabetes Mellitus maka peneliti tertarik untuk mengambil penelitian dengan judul hubungan antara tingkat pengetahuan tentang Diabetes mellitus dan gaya hidup terhadap Tipe

Diabetes Mellitus di Puskesmas Wonodadi Kabupaten Blitar.

\section{METODE}

Desain penelitian yang digunakan adalah cross sectional dan pengambilan sampel serta teknik sampling yang digunakan adalah purposive sampling. Serta memakai kriteria inklusi dan eksklusi yang telah ditetapkan oleh peneliti yaitu kriteria inkulsi dapat berkomunikasi dengan baik dan bersedia menjadi responden. Kriteria ekslusi yaitu pada saat penelitian tidak ada ditempat dan pasien DM yang mengalami masalah kesehatan mendadak seperti pusing, letih dan lemah dan masalah lain yang tidak

memungkinkan untuk menjadi responden. Jumlah populasi dalam penelitian ini yaitu 37 responde dan jumlah sampel pada penelitian ini ada 37 responden.

\section{HASIL PENELITIAN}

Tabel 1 Tingkat Pengetahuan Responden tentang Diabetes Mellitus di Puskesmas Wonodadi Kabupaten Blitar Tahun 2015

\begin{tabular}{ccc}
\hline Kategori & Frekuensi & Persentase (\%) \\
\hline Cukup & 4 & 10,82 \\
Kurang & 33 & 89,18 \\
Jumlah & 37 & 100 \\
\hline
\end{tabular}

(sumber: data primer, 2015)

Berdasarkan Tabel 1. Tingkat pengetahuan responden tentang DM diketahui bahwa sebagian besar responden memiliki pengetahuan dalam kategori kurang sebanyak 33 responden $(89,18 \%)$. 
Tabel 2 Gaya Hidup Responden penderita Diabetes Mellitus di Puskesmas Wonodadi Kabupaten Blitar Tahun 2015

\begin{tabular}{ccc}
\hline Kategori & Frekuensi & Persentase (\%) \\
\hline Sehat & 12 & 32,4 \\
Tidak Sehat & 25 & 67,6 \\
Jumlah & 37 & 100 \\
\hline
\end{tabular}

(sumber: data primer, 2015)

Berdasarkan Tabel 2. Gaya hidup responden penderita DM diketahui bahwa sebagian besar responden memiliki gaya hidup yang tidak sehat yaitu sebanyak 25 responden $(67,6 \%)$.

Tabel 3 Tipe Diabetes Mellitus di Puskesmas Wonodadi Kabupaten Blitar Tahun 2015

\begin{tabular}{ccc}
\hline Diabetes Mellitus & Frekuensi & Persentase (\%) \\
\hline Tipe I & 11 & 29,73 \\
Tipe II & 26 & 70,27 \\
Jumlah & 37 & 100 \\
\hline
\end{tabular}

(sumber: data primer, 2015)

Berdasarkan Tabel 3. Tentang Tipe DM responden menunjukan bahwa DM
Tipe II paling banyak sebesar 26 responden $(70,27 \%)$.

Tabel 4 Hubungan Antara Tingkat Pengetahuan Tentang Diabetes Mellitus Dengan Tipe Diabetes Mellitus di Puskesmas Wonodadi Kabupaten Blitar

Value df Asymp. Sig. (2-sided

\begin{tabular}{llll}
\hline Pearson Chi- & $4.400^{\mathrm{a}}$ & 1 & 0,036
\end{tabular}

Square

(sumber: hasil output uji chi-square data primer tahun 2015)

Berdasarkan Tabel 4. Hasil uji statistik chi square diperoleh hasil $\mathrm{Sig}=$ $0,036<\alpha=0,05$. Hal ini berarti H0 ditolak dan $\mathrm{H} 1$ diterima dan menunjukan bahwa terdapat hubungan antara tingkat pengetahuan entang DM terhadap Tipe DM di Puskesmas Wonodadi Kabupaten Blitar.

Tabel 5 Hasil Analisis Hubungan Antara Gaya Hidup Dengan tipe Diabetes Mellitus di Puskesmas Wonodadi Kabupaten Blitar

\begin{tabular}{|c|c|c|c|}
\hline & Value & df & $\begin{array}{l}\text { Asymp. Sig. (2- } \\
\text { sided }\end{array}$ \\
\hline $\begin{array}{l}\text { Pearson Chi- } \\
\text { Square }\end{array}$ & $3.892^{\mathrm{a}}$ & 1 & 0,049 \\
\hline
\end{tabular}

Berdasarkan Tabel 5. Hasil uji statistik chi square diperoleh hasil $\mathrm{Sig}=$ $0,049<\alpha=0,05$. Hal ini berarti H0 ditolak dan $\mathrm{H} 1$ diterima daan menunjukan bahwa terdapat hubungan antara gaya hidup terhadap Tipe DM di Puskesmas Wonodadi Kabupaten Blitar.

\section{PEMBAHASAN}

Dari data hasil penelitian yang telah diperoleh, pembahasan dilakukan untuk mengetahui tentang hubungan antara tingkat pengetahuan tentang Diabetes Mellitus dan gaya hidup terhadap Tipe Diabetes Mellitus di Puskesmas Wonodadi Kabupaten Blitar.

\section{Tingkat Pengetahuan Responden tentang DM}

Dari hasil penelitian yang telah dilakukan terhadap 37 responden didapatkan sebagian besar tingkat 
pengetahuan responden tentang DM dalam kategori cukup sebanyak 4 responden $(10,82 \%)$. Responden mampu mengetahui faktor-faktor yang dapat menyebabkan DM seperti suka makan makanan yang manis, obesitas, kurang istirahat, namun responden salah

pemahaman terhadap faktor-faktor tersebut. Sebanyak 33 responden $(89,18 \%)$ tingkat pengetahuan dalam kategori kurang. Mereka kurang mengetahui tentang DM. sebagian besar mengalami gejala DM namun mereka tidak mengetahui bahwa itu tanda-tanda dari DM. Mereka juga tidak mengetahui hal-hal apa saja yang dapat meningkatkan kadar gula.

\section{Gaya Hidup Penderita DM di Puskesmas Wonodadi}

Hasil penelitian gaya hidup penderita DM menunjukan gaya hidup responden tidak sehat yaitu sebanyak 25 responden $(67,6 \%)$ dan gaya hidup sehat sebanyak 12 responden $(32,4 \%)$. Responden dengan gaya hidup tidak sehat sebagian besar tidak memiliki kebiasaan makan dengan gizi seimbang, kurang memiliki kebiasaan beraktifitas fisik, dan istirahat kurang dari 6-8jam perhari.

Hal ini sesuai dengan penelitian Hairi (2012) dimana gaya hidup serba santai, serba instan dan canggih sebagai akibat timbulnya DM. makanan semakin beragam, semakin banyak makanan yang berkolesterol tinggi, manis serta berlemak. Dengan gaya hidup seperti itu menyebabkan seseorang tidak memiliki riwatay DM dalam keluarganya dapat menderita DM.

\section{Tipe DM di Puskesmas Wonodadi}

Hasil penelitian Tipe DM menunjukan sebagian besar responden menderita DM Tipe II sebanyak 26 responden $(70,27 \%)$. Secara umum ada dua penyebab utama terjadinya penyakit Diabetes mellitus tipe II ini yaitu faktor genetik (keturunan) dan hiperglikemia (tingginya kadar gula darah). Faktor keturunan sangat berpengaruh dalam
Diabetes mellitus tipe II. Jika orang tua menderita Diabetes maka kemungkinan besar anaknya juga menderita Diabetes. Diabetes pada keturunan ini akan aktif dengan sendirinya manakala dipicu dengan rendahnya tingkat aktifitas sehari-hari, kurang olah raga, pola makan yang salah, gaya hidup yang kurang sehat dan kelebihan berat badan. Saat ini, Diabetes tipe II merupakan jenis Diabetes yang paling banyak di derita dan menyerang orang dari segala usia. Jumlah penderitanya jauh lebih banyak dibandingkan dengan Diabetes tipe I. (Helmawati, 2014).

\section{Hubungan antara Tingkat Pengetahuan tentang DM dengan Tipe DM}

Hasil analisis statistik dalam penelitian ini menunjukan bahwa nilai uji chi square $0,027<\alpha=0,05$ sehingga $\mathrm{H} 0$ ditolak dan hipotesa penelitian ini diterima yaitu ada hubungan antara tingkat pengetahuan tentang diabetes mellitus dengan Tipe diabetes mellitus.

Hasil penelitiaan juga sejalan dengan penelitian yang dilakukan Heriani, 2012 yang berjudul hubungan tingkat pengetahuan tentang penyakit diabetes melitus terhadap mekanisme koping pasien diabetes mellitus dengan nilai 0,021 yang artinya ada hubungan antara tingkat pengetahuan tentang penyakit diabetes mellitus. Hasil ini juga sejalan dengan Nurrahman (2012) yang dikutip dalam Hairi (2012) yang menyatakan bahwa tingkat pengetahuan yang rendah akan dapat mempengaruhi pola makan yang salah sehingga menyebabkan kegemukan. Kurangnya pengetahuan masyarakat tentang diabetes mellitus, mengakibatkan masyarakat baru sadar terkena penyakit diabetes malitus setelah mengalami sakit parah.

\section{Hubungan Gaya Hidup dengan Tipe DM}

Hasil analisis statistik dalam penelitian ini menunjukan bahwa nilai uji chi square $0,049<\alpha=0,05$, sehingga $\mathrm{H} 0$ ditolak dan hipotesa penelitian ini 
diterima yaitu ada hubungan antara gaya hidup dengan tipe diabetes mellitus.

Hasil ini juga sejalan dengan Hairi (2012) yang menyatakan bahwa gaya hidup penderita diabetes mellitus memiliki hubungan dengan kejadian

Diabetes mellitus. Dimana nilai signifikansi yang didapatkan $0,010<\alpha=$ 0,05 maka H0 di tolak.

Gaya hidup kurang bergerak dikaitkan dengan peningkatan risiko untuk gula darah tinggi dan diabetes. Pada orang dengan diabetes, olah raga mengurangi tingkat gula darah. Olah raga juga mengurangi komplikasi kardiovaskular akibat diabetes, termasuk tekanan darah tinggi, penyakit jantung, dan peradangan. (Hasdianah, 2012).

\section{KESIMPULAN}

Penelitian ini dilakukan untuk mengetahui hubungan antara tingkat pengetahuan tentang DM dan gaya hidup terhadap Tipe DM di Puskesmas Wonodadi Kabupaten Blitar. Dari hasil penelitian didapatkan bahwa pengetahuan responden tentang DM dalam kategori kurang, gaya hidup tidak sehat dan Tipe DM yaitu DM Tipe II. Berdasarkan uji statistik menggunakan uji chi square diketahui bahwa ada hubungan antara tingkat pengetahuan tentang DM terhadap Tipe DM di Puskesmas Wonodadi kabupaten Blitar dan ada hubungan antara gaya hidup dengan Tipe DM di Puskesmas Wonodadi Kabupaten Blitar.

\section{SARAN}

1. Bagi Institusi Pendidikan

Bagi institusi pendidikan diharapkan dapat berfungsi sebagai referensi untuk memperoleh pengetahuan tentang Diabetes mellitus dan gaya hidup.

2. Bagi masyarakat

Adanya perubahan gaya hidup atau perilaku yang berpengaruh terhadap Diabetes mellitus. Masyarakat lebih menggali serta mencari informasi tentang Diabetes mellitus sehingga masyarakat bisa merubah gaya hidup yang tidak sehat dan bisa mengurangi resiko terjadinya Diabetes mellitus.

3. Bagi peneliti selanjutnya

Dalampenelitianselanjutnya

diharapkan untuk lebih menggali tentang faktor-faktor lain yang mempengaruhi

gaya hidup. Selain itu perlu mempertimbangkan kelemahankelemahan dalam penelitian ini serta mempertimbangkan faktor lain yang dapat mempengaruhi gaya hidup pada

penderita Diabetes mellitus. Seperti minum-minuman keras, merokok dan mengendalikan stres. Dan diharapkan peneliti selanjutnya bisa menghubungkan variabel lain yang tidak diteliti dalam penelitian ini.

4. Bagi lokasi penelitian

Diharapkan petugas kesehatan lebih memberikan sosialisasi kepada penderita Diabetes mellitus serta pentingnya upaya pencegahan Diabetes mellitus melalui penyuluhan yang dilakukan oleh pihak Puskesmas guna menurunkan resiko terkena Diabetes mellitus serta membuat media cetak berupa poster, benner tentang resiko Diabetes dan pencegahan diabetes. 
DAFTAR RUJUKAN

Dinas Kesehatan Kabupeten Blitar, 2014, Profil Kesehatan Kabupaten Blitar, Dinkes kabupaten Blitar.

Hairi, lalu Muhammad. 2012. Hubungan antara tingkat pengetahuan tentang diabetes mellitus dengan gaya hidup penderita diabetes mellitus tipe ii di desa nyatnyono, kecamatan ungaran barat, kabupaten semarang. http://perpusnwu.web.id/karyailmiah /documents/3472.pdf. [Diakses pada tanggal 6 Desember 2014].

Hasdianah. 2012. Mengenal diabetes mellitus pada orang dewasa dan anak-anak dengan solusi herbal. Yogyakarta: Nuha Medika.

Helmawati, Triana. 2014. Hidup Sehat Tanpa Diabetes. Yogyakarta:
Notebook Kementerian Kesehatan RI, 2013, Riset Kesehatan Dasar, http://www.depkes.go.id/resources/d ownload/general/Hasil\%20Riskesda s\%202013.pdf. [Diakses pada tanggal 14 November 2014].

Heriani, Pebrita.2013. Hubungan tingkat pengetahuan tentang penyakit diabetes mellitus terhadap mekanisme koping pasien diabetes mellitus tipe 2 di RSUD teluk kuantan.

http://repository.unri.ac.id/xmlui/bits tream/handle/123456789/4263/JUR NAL.pdf?sequence $=1 . \quad$ [Diakses pada tanggal 7 Agustus 2015].

Suiraoka. 2012. Penyakit Degeneratif. Yogyakarta: Nuha Medika. 